\title{
EXPERIÊNCIAS COM EDUCAÇÃO PERMANENTE NA ÁREA DA SAÚDE: REVISÃO INTEGRATIVA DA LITERATURA
}

\author{
Vanessa Baliego de Andrade BARBOSA ${ }^{1}$ \\ Silvia Cristina Mangini BOCCHI ${ }^{2}$ \\ Pedro Marco Karan BARBOSA ${ }^{3}$
}

\begin{abstract}
${ }^{1}$ Enfermeira, doutoranda junto ao Programa de Pós-Graduação em Saúde Coletiva da Faculdade de Medicina de Botucatu - Unesp. End: Rua: Plinio Amaral, 612 casa 45, Jd. Itaipu. CEP: 17.519.520. Marília, São Paulo, Brasil. Fone:+551434178584. E-mail: baliego@famema.br

${ }^{1}$ Enfermeira, Professora Doutora junto ao Departamento de Enfermagem da Faculdade de Medicina de Botucatu Unesp. Fone: +551438801314. E-mail: sbocchi@fmb.unesp.br

${ }^{3}$ Enfermeiro, Professor Doutor do Curso de Enfermagem da Faculdade de Medicina de Marília - Famema. Fone:+551434178584. E-mail: karan@famema.br
\end{abstract}

Recebido em: 15/05/2014 - Aprovado em: 30/06/2014 - Disponibilizado em: 30/07/2014

\begin{abstract}
RESUMO
Revisão integrativa da literatura para compreender a experiência de profissionais da saúde com a educação permanente (EP) como estratégia de formação de recursos humanos. Para seleção dos artigos utilizou-se as bases Medical Literature Analysis and Retrieval System on-line (MEDLINE) e Literatura latino-Americana e do Caribe em Ciências da Saúde (LILACS). Segundo os critérios de inclusão e exclusão oito publicações foram selecionadas e analisadas por meio da análise de conteúdo. Dois temas emergiram: EP como espaço de escuta, diálogo e integração dos trabalhadores; vivenciando mudanças na prática a partir dos movimentos de EP contribuindo para a autonomia e segurança nas tomadas de decisões. Conclui-se que a decisão de utilizar da educação permanente para a formação dos trabalhadores de saúde ainda se configura em uma atitude ousada, pois é necessário romper com os modelos de gestão autoritários e os processos de cuidar centralizados no profissional de saúde e não no usuário.

Palavra Chave: enfermagem. educação continuada. gestão em saúde. administração de recursos humanos.
\end{abstract}

\begin{abstract}
ABSTRAT
Integrative literature review to understand the experience of health care professionals with continuing education (CE) as a strategy for human resource training. To select the articles we used the bases Medical Literature Analysis and Retrieval System on-line (MEDLINE) and Literatura latino-Americana and from Caribe em Ciências da Saúde (LILACS). According to the criteria of inclusion and exclusion eight publications were selected and analyzed using content analysis. Two themes emerged: $\mathrm{CE}$ as a space for listening, dialogue and integration of workers; experiencing changes in practice from the movements of CE contributing to the security and autonomy in decision making. We concluded that the decision to use continuing education for the training of health workers still set in a bold move, it is necessary to break with the authoritarian management models and processes of care-centered health care and not the user.
\end{abstract}

Keywords: nursing continuing education, health management, human resource administration.

\section{RESUMEN}

Revisión de la literatura de integración para comprender la experiencia de profesionales de la salud con la educación continua (EC) como estrategia de formación de recursos humanos. Para seleccionar los artículos se utilizaron como base: "Medical Literature Analysis and Retrieval System on-line [Análisis de la Literatura Médica y Sistema de Recuperación] (MEDLINE), y "Literatura Latino-Americana e do Caribe em Ciências da Saúde" [Literatura LatinoAmericana y del Caribe en Ciencias de la Salud] (LILACS). De acuerdo a los criterios de inclusión y exclusión, ocho publicaciones fueron seleccionadas y analizadas por medio del análisis de contenido. Surgieron dos temas: EC como espacio de escucha, dialogo e integración de los trabajadores, experimentando cambios en la práctica a partir de los movimientos de EC, que contribuyen para la autonomía y seguridad en la toma de decisiones. Se concluye que la decisión de utilizar la educación continua para la formación de los trabajadores de salud, todavía constituye una actitud audaz, porque es necesario romper con modelos de gestión autoritarios y procesos de atención de salud, centralizados en el profesional de la salud y no en el usuario.

Palabra clave: enfermería; educación continua; gestión en salud; administración de recursos humanos. 


\section{INTRODUÇÃO}

A Educação Permanente (EP) se apresenta como estratégia potente de capacitação dos profissionais da saúde, favorecendo a reflexão da prática e transformação dos processos de trabalho, visto que a educação não pode estar voltada apenas para a busca eficiente de evidências diagnósticas, tratamento, prognóstico, etiologia e profilaxia das doenças, mas também deve estar pautada no levantamento das necessidades de saúde das pessoas, da gestão local e do controle social.

A gestão de serviços de saúde configura-se em uma prática que o profissional vivencia em seu dia-a-dia e, por muitas vezes, não dispõe de ferramentas que o auxiliem neste processo.

Repensar a organização do trabalho torna-se um desafio, principalmente quando se considera que as pessoas têm diferentes pensamentos e valores agregados à sua história de vida, fato que deve ser reconhecido quando se pretende estabelecer mudanças, sejam elas relacionadas ao conhecimento, atitudes e/ou habilidades.

Existe um reconhecimento internacional da necessidade de mudanças no processo ensino aprendizagem dos profissionais de saúde, diante da inadequação do aparelho formador, para responder às demandas advindas do mundo moderno. As instituições têm sido estimuladas a voltar seu ensino para as diretrizes do Sistema Único de Saúde, aliando a qualidade da assistência à eficiência e à relevância do trabalho em saúde (CYRINO; TORALLES-PEREIRA, 2004).

A educação é entendida como o processo de encontrar dentro da pessoa o que nela já existe, ou expor o que está dentro dela (SAUPE; BUDÓ, 2006).

As relações durante $\mathrm{o}$ processo educativo necessitam ser construídas partindo-se do princípio de que todos possuem um conhecimento advindo da sua vivência anterior, considerando a sua inserção cultural na comunidade, bem como de sua forma de viver e se organizar, não sendo os indivíduos considerados como "caixas vazias", cada um sempre tem algo a contribuir na construção do conhecimento (BRASIL, 2005).

Diante do exposto, a EP se configura como uma ação estratégica para a aprendizagem coletiva a partir das práticas e do trabalho, oportunizando o diálogo e a cooperação entre os profissionais, serviços, gestão, atenção, formação e controle social, potencializando o enfrentamento e a resolução de problemas com qualidade (BRASIL, 2005).

No entanto, a educação permanente tem sido recomendada por muitos autores como um processo potente na formação dos profissionais da saúde, mas com poucos relatos de como se conduz na prática.

A EP explicita uma nova posição sobre a saúde e o processo de educação de adultos, 
revelando ser um instrumental potente na transformação da prática dos profissionais da saúde. Diferentemente da noção programática de implementação de práticas previamente selecionadas e com um currículo dirigido ao treinamento de habilidades, a política de EP em saúde congrega, articula e coloca em rede diferentes atores, destinando a todos um lugar de protagonismo na condução dos sistemas locais de saúde (CECCIM, 2005).

A contento, faz-se necessário entendermos se a EP tem sido utilizada para o processo de formação, uma vez que hoje são exigidas dos profissionais novas formas de atuação, de enfrentamento dos problemas com o objetivo de identificar as necessidades desses que cuidam do paciente, visando o atendimento integral à saúde.

Em face ao apresentado, pergunta-se: Como se configura a produção do conhecimento acerca das experiências de profissionais de instituições de saúde que se utilizam da EP como estratégia de formação e gestão do trabalho em saúde?

Para responder à inquietação, pretendese com esta investigação levantar e apresentar de forma sistematizada esse conhecimento.

\section{MÉTODO}

Trata-se de revisão integrativa da literatura, para realizar uma síntese da produção científica, identificando consensos, complementos e divergências dos especialistas referente a uma determinada prática com pouco conhecimento científico produzido para sua fundamentação . (BEYEA; NICOLL, 1998)

A Medical Literature Analysis and Retrieval System on-line (MEDLINE) e a Literatura latino-Americana e do Caribe em Ciências da Saúde (LILACS) foram as bases de dados escolhidas para a seleção dos artigos que fizeram parte do corpus da análise:. A combinação de palavras-chave utilizada na base de dados LILACS foram "educação" and "permanente" e no módulo refinar foram inseridas as palavras-chave "enfermagem" and "Hospital". Na base de dados MEDLINE, as combinações de palavras usadas foram "education" and "permanent" and "nursing". Para seleção dos artigos foram utilizados os seguintes critérios de inclusão: publicações disponíveis em texto completo, em periódicos, dissertações e teses, nos idiomas, português e inglês e que retratassem a experiência com a educação permanente.

Os artigos foram selecionados a partir da busca nas bases de dados em todo período de suas existências até Fevereiro de 2012. Surgiram 50 artigos no LILACS, que após leitura dos resumos, segundo os critérios de inclusão e exclusão foram selecionados apenas seis, enquanto no MEDLINE dos 70 artigos ficaram somente dois. Muitos deles foram subtraídos por apenas recomendar a implantação da EP, mas não a realizavam de fato.

Desta forma, identificaram-se oito publicações sendo sete artigos e uma dissertação de mestrado, os quais foram 
analisadas por meio da Análise de Conteúdo (BARDIN, 1977), na modalidade temática e os resultados serão apresentados no Quadro e serão discutidos em dois temas: EP como espaço de escuta, diálogo e integração dos trabalhadores; vivenciando mudanças na prática a partir dos movimentos de EP contribuindo para a autonomia e segurança nas tomadas de decisões.

O conhecimento produzido pela literatura será discutido á luz da pedagogia libertadora (FREIRE,2001).

\section{RESULTADOS}

As pesquisas selecionadas apontaram para a experiência em realizar a EP em instituições de saúde. Dentre elas a maioria $(87,5 \%)$ são artigos publicados em revistas nacionais e $(12,5 \%)$ dissertações de mestrado, os quais estão identificados nas referências com asterisco.

A abordagem qualitativa predominou $(87,5 \%)$ como tipo de pesquisa, destacando o Estado de Minas Gerais (37,5\%) como produtor de estudos com o objeto de investigação experiência com EP, seguido do Rio Grande do Sul (37,5\%), São Paulo e Distrito Federal com 12,5\%.

As publicações se concentraram (50\%) em 2010 e 12,5\%, igualmente, para os anos de 2006, 2009, 2008 e 2011.

A categoria profissional que mais publicou foi à enfermagem $(87,5 \%)$, ficando com $(12,5 \%)$ os cirurgiões dentistas.
Segue síntese da análise das pesquisas levantadas, que constituíram o corpus da análise, sendo que cada publicação encontrase identificada com a letra $\mathrm{P}$ e o número correspondente (Quadro 1). 
Quadro -1. Síntese das publicações que constituíram o corpus da análise.

\begin{tabular}{|c|c|c|c|}
\hline Pesquisa/Tipo & Objetivo & Resultados & Conclusões \\
\hline $\begin{array}{l}\text { P1- } \\
\text { Autores: Amestoy et al. } \\
\text { Ano: } 2010 \\
\text { Tipo de estudo: qualitativo, } \\
\text { Estado: Rio Grande do Sul } \\
\text { Autores: Enfermeiros } \\
\end{array}$ & $\begin{array}{l}\text { Conhecer o papel de uma } \\
\text { instituição de ensino superior e } \\
\text { hospitalar na formação e educação } \\
\text { permanente de enfermeiros-líderes. }\end{array}$ & $\begin{array}{l}\text { Emergiram duas categorias para discussão: } \\
\text { - O papel da Instituição de ensino Superior na } \\
\text { formação de Enfermeiros-líderes } \\
\text { - O papel da instituição hospitalar na educação } \\
\text { permanente de enfermeiros-líderes }\end{array}$ & $\begin{array}{l}\text { O estudo revela que há existência de lacunas na formação } \\
\text { do enfermeiro líder, principalmente no processo de ensino } \\
\text { aprendizagem, onde se evidencia pouco tempo ao ensino } \\
\text { desta competência e um distanciamento do docente da } \\
\text { prática assistencial. Também identificou um escasso } \\
\text { incentivo referente a prática de educação permanente. }\end{array}$ \\
\hline $\begin{array}{l}\text { P2- } \\
\text { Autores: Montanha, } \\
\text { Peduzzi (2010) } \\
\text { Tipo de estudo: qualitativo } \\
\text { Estado: São Paulo } \\
\text { Autores: Enfermeiros }\end{array}$ & $\begin{array}{l}\text { Analisar o levantamento de } \\
\text { necessidades para a implantação } \\
\text { de atividades educativas de } \\
\text { trabalhadores de enfermagem e os } \\
\text { resultados esperados com a } \\
\text { realização dessas atividades. }\end{array}$ & $\begin{array}{l}\text { Emergiram as seguintes categorias: } \\
\text {-levantamento de necessidades com base em } \\
\text { problemas, na supervisão de enfermagem, no } \\
\text { espaço de troca usuário-serviço, em solicitação } \\
\text { dos trabalhadores de nível médio e na articulação } \\
\text { com outras áreas. } \\
\text {-Resultados esperados, melhora do desempenho } \\
\text { técnico, diminuição de falhas no procedimento, } \\
\text { ampliação da reflexão e crítica do trabalho, evitar } \\
\text { vícios na execução do trabalho, ampliar a } \\
\text { autonomia dos trabalhadores de enfermagem, } \\
\text { uniformidade de condutas e definição de suas } \\
\text { atribuições. }\end{array}$ & $\begin{array}{l}\text { As ações educativas para as trabalhadoras a curto prazo, } \\
\text { assinalam a melhoria na qualidade, do desempenho técnico } \\
\text { e diminuição das falhas nos procedimentos, valorizando a } \\
\text { ciência como fonte de conhecimento, a primazia da } \\
\text { dimensão técnica do trabalho e a concepção de Educação } \\
\text { continuada. Em médio e longo prazo os resultados } \\
\text { deslocam-se para a ampliação da reflexão crítica do } \\
\text { trabalho, bem como da interação profissional/usuário, e a } \\
\text { articulação teoria e prática, numa evidente concepção de } \\
\text { educação permanente. }\end{array}$ \\
\hline $\begin{array}{l}\text { P3 } \\
\text { Autores: Nunes et al. } \\
\text { (2008) } \\
\text { Tipo de estudo: quanti- } \\
\text { qualitativo, } \\
\text { Estado; Distrito Federal } \\
\text { Autores: Cirurgiões } \\
\text { Dentistas }\end{array}$ & $\begin{array}{l}\text { Desenvolvimento profissional dos } \\
\text { cirurgiões dentistas da rede pública } \\
\text { de saúde nos Estados e municípios } \\
\text { brasileiros, por meio de ações de } \\
\text { educação permanente, buscando a } \\
\text { ação integral e humanizada às } \\
\text { pessoas vivendo com HIV/Aids }\end{array}$ & $\begin{array}{l}\text { Fica evidente a atuação dos profissionais } \\
\text { facilitadores que deixaram a atitude passiva, } \\
\text { resistente e pouco comprometida dos cirurgiões } \\
\text { dentistas para uma postura mais proativa e crítica, } \\
\text { com o surgimento de novas competências e } \\
\text { habilidades de comunicação, negociação e } \\
\text { pactuação de propostas e soluções. A estratégia de } \\
\text { educação mostrou-se acertada e indicou } \\
\text { dificuldades, desde a sua compreensão como } \\
\text { referencial teórico, mas também como estratégia } \\
\text { de construção de políticas intersetoriais. Outro } \\
\text { aspecto importante foi à articulação ensino } \\
\text { /serviço com as instituições de ensino públicas } \\
\text { estaduais e federais nos estados e municípios. }\end{array}$ & $\begin{array}{l}\text { Os processos ativos de formação proporcionam trocas, } \\
\text { realizam transformações, levam ao desenvolvimento e } \\
\text { conduta positiva do cirurgião dentista do serviço público e } \\
\text { proporcionam às pessoas a atenção de que necessitam, } \\
\text { aumentam a autonomia dos sujeitos, criam } \\
\text { responsabilidades e comprometimentos, desmistificam } \\
\text { crenças e aumentam saberes. }\end{array}$ \\
\hline
\end{tabular}




\begin{tabular}{|c|c|c|c|}
\hline $\begin{array}{l}\text { P4 } \\
\text { Jesus et al. (2011) } \\
\text { Tipo de estudo: qualitativo } \\
\text { Estado: Minas Gerais } \\
\text { Autores: Enfermeiros }\end{array}$ & $\begin{array}{l}\text { Identificar } \quad \text { demandas } \\
\text { expectativas, } \\
\text { interferem na qualores que } \\
\text { trabalhadores de enfermagem de } \\
\text { um hospital universitário, e propor } \\
\text { práticas de capacitação na } \\
\text { perspectiva da educação } \\
\text { permanente. }\end{array}$ & $\begin{array}{l}\text { Emergiram três categorias a serem discutidas: } \\
\text { demandas e expectativas de qualificação para o } \\
\text { trabalho de enfermagem; fatores que interferem } \\
\text { nas práticas de capacitação e capacitação na } \\
\text { perspectiva da educação permanente. }\end{array}$ & $\begin{array}{l}\text { A construção coletiva do conhecimento provocou um } \\
\text { sentimento de pertencimento ao grupo de valorização a } \\
\text { partir da percepção do espaço para serem ouvidos. } \\
\text { Despertou a compreensão sobre a importância do } \\
\text { envolvimento e responsabilização com sua própria } \\
\text { educação profissional e o enfermeiro líder da equipe de } \\
\text { enfermagem, coloca-se como facilitador da ação educativa } \\
\text { com os auxiliares e técnicos de enfermagem. }\end{array}$ \\
\hline $\begin{array}{l}\text { P5 } \\
\text { Rodrigues et a } \\
\text { Tipo de estudo } \\
\text { Estado: Minas } \\
\text { Autores: Enfe }\end{array}$ & $\begin{array}{l}\text { Relatar a experiência do processo } \\
\text { de educação permanente em saúde } \\
\text { por meio de oficinas educativas em } \\
\text { Diabetes, na atualização da equipe } \\
\text { de Saúde da Família em uma } \\
\text { Unidade Básica de Saúde para a } \\
\text { atenção integral e humanizada aos } \\
\text { usuários com diabetes tipo } 2 \text {. }\end{array}$ & 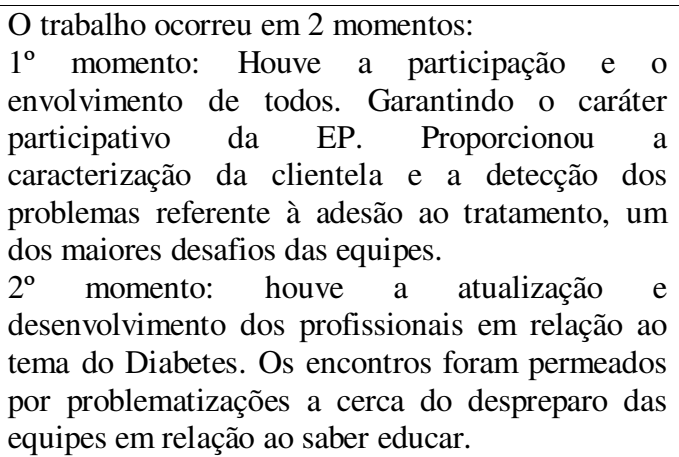 & $\begin{array}{l}\text { O processo de Educação Permanente em Saúde, contribui } \\
\text { para melhorar a qualificação dos profissionais, uniformizar } \\
\text { e sistematizar um atendimento ao usuário com diabetes em } \\
\text { em termos da integralidade, educação em saúde e } \\
\text { desenvolvimento do autogerenciamento. Esta experiência } \\
\text { colaborou para o progresso da integração entre } \\
\text { universidade, serviço e comunidade, preparando os } \\
\text { profissionais por meio do desenvolvimento da capacidade } \\
\text { crítica e criativa a fim de atuarem em atividades educativas } \\
\text { junto à população. }\end{array}$ \\
\hline $\begin{array}{l}\text { P6 } \\
\text { Autores: Medeiros et al. } \\
\text { (2010) } \\
\text { Tipo de estudo: qualitativo } \\
\text { Estado: Rio Grande do Sul } \\
\text { Autores: Enfermeiros }\end{array}$ & $\begin{array}{l}\text { Conhecer as estratégias de gestão, } \\
\text { construídas pelas enfermeiras de } \\
\text { uma UTI, com base na Educação } \\
\text { Permanente e } \\
\text { m Saúde. }\end{array}$ & $\begin{array}{l}\text { Foram identificadas duas temáticas para serem } \\
\text { discutidas: planejamento participativo e tomada } \\
\text { de decisões. }\end{array}$ & $\begin{array}{l}\text { A gestão participativa e a tomada de decisão com base na } \\
\text { EPS: fortalece e valoriza o trabalho em equipe, viabiliza a } \\
\text { participação dos profissionais no planejamento e ações do } \\
\text { cuidado, estimula o compromisso com a democratização } \\
\text { das relações de trabalho, cria e facilita espaços de trocas e } \\
\text { produção do conhecimento no coletivo, amplia o diálogo } \\
\text { entre a equipe de saúde. }\end{array}$ \\
\hline $\begin{array}{l}\text { P7 } \\
\text { Autores: Ricaldoni, Sena } \\
\text { (2006) } \\
\text { Tipo de estudo: qualitativo, } \\
\text { Estado: Minas Gerais } \\
\text { Autores: Enfermeiros }\end{array}$ & $\begin{array}{l}\text { Analisar os efeitos das ações de } \\
\text { educação permanente na qualidade } \\
\text { da assistência de enfermagem, em } \\
\text { um hospital privado de grande } \\
\text { porte, no município de Belo } \\
\text { Horizonte, MG. }\end{array}$ & $\begin{array}{l}\text { Foi possível a construção de duas categorias } \\
\text { empíricas a serem discutidas: Processo de } \\
\text { trabalho e educação permanente }\end{array}$ & $\begin{array}{l}\text { A análise dos dados empíricos deste estudo, mostra uma } \\
\text { desarticulação da capacitação realizada no hospital com o } \\
\text { processo de trabalho do administrar e cuidar. Sendo } \\
\text { necessário investir no processo de capacitação voltado } \\
\text { para a metodologia da problematização. Foi possível } \\
\text { observar que ocorreram algumas mudanças principalmente } \\
\text { a abordagem conceitual e metodologica da educação. } \\
\text { Observou-se também a possibilidade de ocorrerem } \\
\text { mudanças referente relação social do indivíduo como } \\
\text { sujeito que presta cuidado ao paciente. }\end{array}$ \\
\hline $\begin{array}{l}\text { P8 } \\
\text { Autor: Brum (2009) }\end{array}$ & $\begin{array}{lccc}\text { Analisar os } & \text { limites } & \text { e } & \text { as } \\
\text { potencialidades } & \text { do } & \text { uso } & \text { da }\end{array}$ & $\begin{array}{l}\text { Foi possível identificar categorias e subcategorias } \\
\text { analíticas: A reinvenção da roda: caminho para a }\end{array}$ & $\begin{array}{l}\text { O contexto hospitalar ainda permanece fortemente } \\
\text { influenciado pelo pressuposto de que o conhecimento }\end{array}$ \\
\hline
\end{tabular}

156

Revista da Universidade Vale do Rio Verde, Três Corações, v. 12, n. 1, p. 151-167, jan./jul. 2014 


\begin{tabular}{|c|c|c|c|}
\hline $\begin{array}{l}\text { Tipo de estudo: qualitativo, } \\
\text { Estado: Rio Grande do Sul } \\
\text { Autor: Enfermeiro } \\
\text { Tipo de publicação: } \\
\text { Dissertação de mestrado }\end{array}$ & $\begin{array}{l}\text { pedagogia da roda como } \\
\text { dispositivo para ações de educação } \\
\text { permanente de equipes de } \\
\text { enfermagem de um hospital } \\
\text { universitário, com enfoque na } \\
\text { integralidade das práticas de saúde } \\
\text { e levando em conta as experiências } \\
\text { dos sujeitos dessas ações. }\end{array}$ & $\begin{array}{l}\text { educação permanente na enfermagem ( ampliando } \\
\text { os espaços pedagógicos e aprendizagem } \\
\text { significativa no trabalho)A Educação permanente: } \\
\text { potência para a construção da integralidade do } \\
\text { cuidado (valorizando o cuidado e criando } \\
\text { possibilidades de integralidade e limites para a } \\
\text { integralidade) }\end{array}$ & $\begin{array}{l}\text { definem as práticas e segue utilizando metodologias de } \\
\text { transmissão do conhecimento em seus espaços de } \\
\text { educação dos trabalhadores. Apesar das dificuldades } \\
\text { encontradas pelas equipes de enfermagem em integrar as } \\
\text { rodas de Conversa, devido ao trabalho técnico } \\
\text { fragmentado a proposta se apresentou viável no seu } \\
\text { cotidiano do trabalho como um espaço de criação e } \\
\text { manutenção de encontros para diálogo e escuta entre os } \\
\text { trabalhadores propiciou a aprendizagem coletiva, } \\
\text { possibilitando o rompimento com a tradicional lógica } \\
\text { tecnicista do trabalho da enfermagem hospitalar. Para que } \\
\text { a integralidade do cuidado seja realmente uma realidade } \\
\text { faz-se necessário que as rodas de conversa sejam } \\
\text { compostas por uma equipe multiprofissional o que não foi } \\
\text { possível neste estudo. }\end{array}$ \\
\hline
\end{tabular}




\section{DISCUSSÃO}

\section{Tema A. EP como espaço de escuta, diálogo e integração dos trabalhadores}

Das nossas experiências vivenciadas, o processo de trabalho nos hospitais está organizado no modelo biomédico, valorizando a doença, com pouco envolvimento entre os profissionais e priorizando o saber técnico. Um modelo de assistência hierarquizado, fragmentado e fundamentado em uma lógica técnicoburocrática.

Este cenário propicia uma desarticulação entre os profissionais e uma prática solitária que impedem sua capacidade crítica - reflexiva. A propósito, o Ministério da Saúde implementa a Política Nacional de Humanização (PNH), com ferramentas e dispositivos para consolidar redes, vínculos e a coresponsabilização entre usuários, trabalhadores e gestores . (BRASIL, 2007a)

Neste caminho, a busca de humanização e a valorização dos sujeitos fazem parte do processo de produção de saúde. Sendo assim, as discussões dão ênfase aos trabalhadores de saúde, que segundo os valores da humanização devem ser protagonistas dos processos de trabalho, co-responsáveis e participantes na

gestão, necessitando estabelecer vínculos solidários (BRASIL, 2007a)

Colocar os trabalhadores como protagonistas dos processos de trabalho no contexto hospitalar trata-se de um desafio, pois significa promover momentos de pausa em suas atividades cotidianas e romper com as concepções de educação, que ainda predominam pautados nas metodologias de transmissão de conhecimento. No entanto, quando se reconhece e se estabelece a EP como ferramenta para oportunizar o envolvimento dos trabalhadores no processo de sua aprendizagem e coresponsáveis por fazerem a diferença na produção do cuidado, percebe-se sua potência em promover espaços de escuta e diálogo a estes sujeitos, como evidenciamse nos estudos desta revisão:

\begin{tabular}{|c|}
\hline $\begin{array}{l}{[\ldots] \text { O trabalho }} \\
\text { construção coletiva } \\
\text { conhecimento provocou } \\
\text { sentimento } \\
\text { pertencimento ao grup } \\
\text { de valorização a partir } \\
\text { percepção do espaço } \\
\text { serem ouvidos. Despert } \\
\text { compreensão sobre } \\
\text { importância } \\
\text { envolvimento } \\
\text { responsabilização com } \\
\text { própria educa } \\
\text { profissional [...] (P4). } \\
\text { As rodas de conversa } \\
\text { foram reconhecidas } \\
\text { valorizadas pelos suje } \\
\text { da pesquisa, c } \\
\text { importantes espaços } \\
\text { escuta e diálogo para } \\
\text { trabalhadores. }\end{array}$ \\
\hline
\end{tabular}




\begin{abstract}
espaços favoreceu 0 envolvimento e a responsabilização desses sujeitos com o processo pedagógico aí constituído, fazendo emergir novos saberes e práticas [...] (P8).
\end{abstract}

Os espaços de escuta e diálogo se tornam essenciais quando se fundamenta na discussão de que o fator humano e o relacionamento entre os profissionais são fundamentais nos processos de cuidar, compondo com as tecnologias e os dispositivos organizacionais na área da saúde. (BRASIL, 2007b)

Tem-se que se considerar o quão potente é trabalhar com as tecnologias de escuta e negociação das regras comportamentais e organizacionais, visto que as tecnologias leves, que dizem respeito à produção de vínculos, acolhimento, autonomização e gestão do processo de trabalho, correspondem às principais reestruturações produtivas do setor saúde (MERHY, 2002).

No processo de aprendizagem, a escuta é fator essencial por significar a disponibilidade permanente por parte do sujeito que se propõe se abrir para a fala do outro e assim às diferenças e aos gestos do outro. A verdadeira escuta é a possibilidade que cada sujeito que está envolvido no processo de aprendizagem tem de repensar suas concepções e não o diminui em nenhum momento na capacidade de discordar, se opor ou se posicionar e sim ao exercê-la na integra, possibilita o sujeito a se preparar melhor para discorrer sobre suas ideias. Pois ensinar não é transferir a inteligência do objeto ao outro, mas instigá-lo a ser capaz de refletir e comunicar sua nova concepção do objeto (FREIRE,1999).

A escuta qualificada pode ser vista como um processo transparente que constitui uma rede de conversação, favorecendo a abertura de questões, compartilhamento de aspirações, questionamentos e a interação com o todo, buscando a pluralidade de ideias se conformando em uma rede de comunicação (DURÃES - PEREIRA, 2007)

A comunicação se apresenta como uma dimensão indispensável para a assistência à saúde, constituindo-se em um recurso que estabelece a confiança e o vínculo entre os profissionais, considerando a comunicação como algo em que se fazem juntos, levando informação e conhecimento um para o outro de forma clara e compreensível, partindo do princípio que para que isso ocorra se faz necessário ouvir livremente uns aos outros (CHIESA E VERÍSIMO, 2001)

Assim como a escuta, o diálogo merece destaque na EP, pois está sustentado pela interlocução entre os sujeitos e na essência da intersubjetividade, 
ele é relacional e ninguém tem iniciativa absoluta. A aprendizagem acontece por meio da conscientização. A consciência emerge do mundo vivido, objetiva-o, problematiza-o compreendendo como projeto humano (FREIRE, 2001).

O diálogo entre os sujeitos sobre a realidade é considerar o reconhecimento do outro e o reconhecimento de si no outro, é decisão e compromisso de colaborar na construção de uma nova realidade, ou seja, de um mundo comum (FREIRE, 2001).

Neste sentido, evidencia-se a potência que os processos dialógicos tem quando favorecidos nas instituições de saúde como mostrou a pesquisa 5:

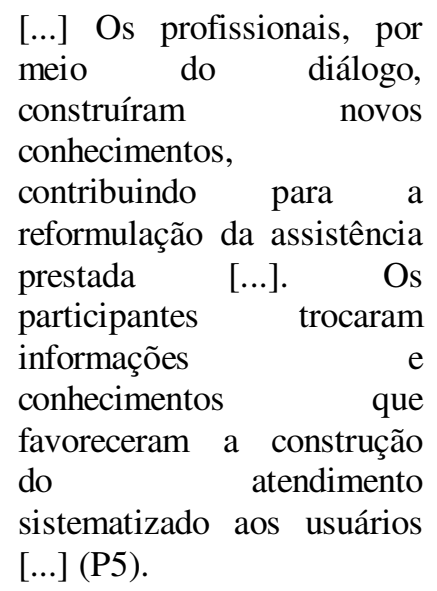

Os espaços de Educação Permanente são reconhecidos como aqueles que oportunizam os diálogos, pois pressupõem um coletivo de trabalhadores, que juntos são responsáveis pela construção de conhecimento, sendo que para isso é necessário trazer para estes espaços os problemas vivenciados na prática, assim, segundo Campos 2007, estes espaços legítimos de diálogo caracteriza a produção de uma obra conjunta, com a contribuição singular de cada um e a co-participação de todos como sujeitos dessa organização.

A reflexão acima remete a compreensão de que ao oportunizar os espaços de escuta e diálogo, as relações entre os trabalhadores também se estreitam fortalecendo a integração entre os mesmos e qualificando o cuidado ao paciente, como poder-se identificar nos artigos analisados:

[...] As discussões sobre medos e preconceitos sobre o que é real e o que é fruto do desconhecimento, desmistificam e melhoram a relação entre cirurgiõesdentistas e usuários das ações e serviços de odontologia que vivem com HIV/Aids [...] (P3). [...] Gradativamente houve um maior entrosamento do grupo, favorecendo as discussões referentes às complicações apresentadas pela doença. Observou-se o estabelecimento de uma relação horizontal e dialógica, do ponto de vista do relacionamento humano entre a equipe, permeada pela confiança [...]. Os processos educativos foram avaliados positivamente pelos profissionais que enfatizaram os benefícios do aprendizado e do estreitamento de relações [...] (P5). Neste espaço interativo/relacional a potência da equipe está justamente no crescimento 
coletivo às possibilidades de expressar as diferenças de opiniões, sentimentos, ideias, são processos de democratização [...] (P6).

A possibilidade de convivência entre os profissionais, que são favorecidos quando implantamos a EP, contribui para a formação de vínculos entre a equipe representando um potencial para ampliar a capacidade de análise do coletivo na direção da realização pessoal, estabelecendo compromissos e construção de contratos (CAMPOS, 2007).

Quando os profissionais se integram e têm a oportunidade de repensar seu processo de trabalho, acontecem também um envolvimento de saberes, amplia-se a capacidade de análise e de coresponsabilidades, compondo assim um espaço de poder compartilhado possibilitando a ampliação significativa da aprendizagem no trabalho, estimulando o compromisso pelos processos e resultados (BRASIL,2005)

Neste sentido, quando as relações entre os trabalhadores estão fortalecidas e os espaços para reflexão da prática consolidados, significa que o primeiro passo para uma gestão compartilhada está dado, pois para que esta gestão aconteça é necessário que as pessoas se abram para o conviver, possibilitando a criação de uma nova realidade, podendo acontecer $\mathrm{o}$ consenso ou a divergência, mas com um objetivo único, a construção de um projeto comum (MATURANA, 1998)

A gestão participativa é um valioso instrumento para a construção de mudanças nos modos de gerir e nas práticas de saúde, contribuindo para tornar o atendimento mais eficaz/efetivo e motivar as equipes de trabalho. A cogestão é um modo de administrar que inclui o pensar e o fazer coletivo, sendo portanto uma diretriz que visa democratizar as relações na saúde (BRASIL, 2009)

Diante do exposto fica evidente que a EP se configura como uma ação estratégica para a aprendizagem coletiva a partir das práticas e do trabalho, oportunizando o diálogo e a cooperação entre os profissionais, serviços, gestão, atenção, formação e controle social potencializando o enfrentamento e a resolução de problemas com qualidade (BRASIL, 2005).

Acredita-se que a realização da EP encontra-se no início de sua prática, sendo necessário expandir para outras categorias profissionais, pois a Enfermagem recebe destaque nas pesquisas avaliadas. No entanto, percebe-se que a possibilidade dos profissionais serem protagonistas do seu processo de trabalho, estarem abertos para a escuta do outro e dialogarem com seus pares contribui para a aprendizagem, que acontece por meio da conscientização, 
decisão e compromisso em transformar a realidade.

A EP favorece a relação entre os profissionais e possibilita que novos pactos de organização do trabalho sejam produzidos, por meio de intervenções articuladas e não fragmentadas aproximando os serviços de saúde dos conceitos de humanização, integralidade e qualidade no cuidado ao usuário.

Tema B. Vivenciando mudanças na prática a partir dos movimentos de EP para a autonomia e segurança nas tomadas de decisões

Ao se deparar com a EP, identificouse como eixo estruturante a proposta metodológica, sustentada pela educação problematizadora que trabalha a construção de conhecimentos a partir da vivência de experiências significativas, apoiadas nos processos de aprendizagem por descoberta, em que os conteúdos são oferecidos ao aluno sob a forma de problemas e não prontos, sendo seu eixo básico a relação ação-reflexão-ação transformadora (CYRINO; TORALLESPEREIRA, 2004)

A transformação da prática é o objetivo final que se quer atingir quando se pensa em implantar os processos de EP. Para este fim, o momento fundamental é o da reflexão crítica sobre a prática. É pensando criticamente na prática de hoje que se pode melhorar a próxima.
Concorda-se com Paulo Freire ao dizer que a pessoa se torna capaz de mudar quanto se reconhece como é ou está e porque está sendo assim (FREIRE, 1999)

Ao analisar as pesquisas percebeu-se que se concretiza a capacidade de intervir na realidade de forma criativa $\mathrm{e}$ responsável, pois quando os sujeitos refletem juntos sobre a realidade que é comum a todos, é possível transformá-la e este processo é denominado como práxis, ação - reflexão - ação, proposta efetiva de transformação (FREIRE, 2001)

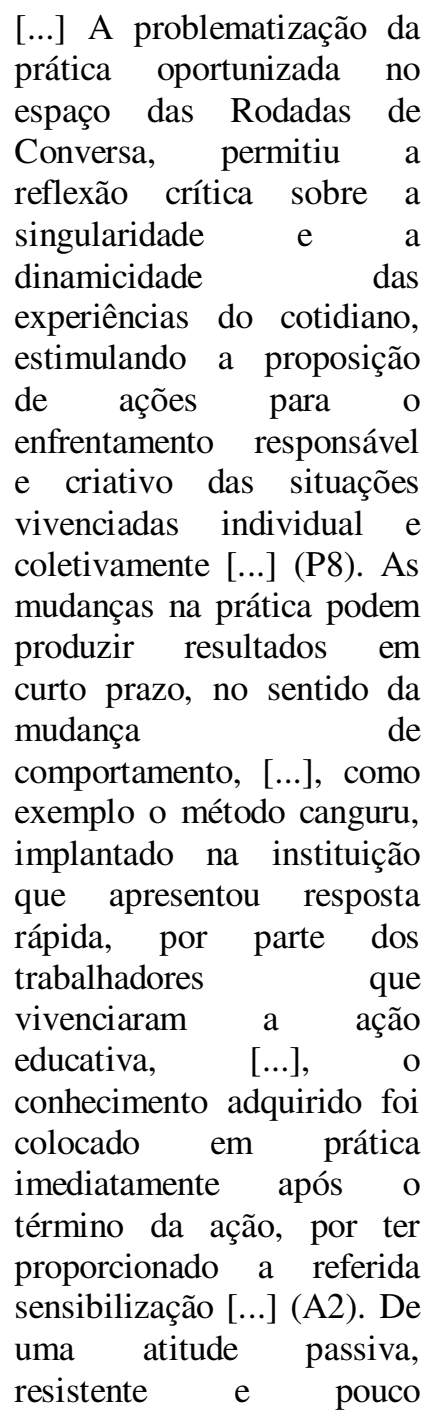




\begin{abstract}
comprometida dos
cirurgiões-dentistas, no

início do processo de

formação, foi-se

desenvolvendo uma postura

mais proativa e crítica, com

o surgimento de novas

competências e habilidades

de comunicação,

negociação e pactuação de

propostas e soluções. Há

relatos de mudança

especialmente no ambiente

de trabalho, quanto ao

controle de infecção,

biossegurança e nas

questões relativas à

estrutura do serviço, como por exemplo, reformas das unidades de saúde e aquisição de equipamentos e materiais de consumo [...] (A3).
\end{abstract}

Quando se reflete sobre a mudança das práticas, acredita-se que o ser humano tem a capacidade de aprender, repensar e não apenas se adaptar às novas práticas, mas sim de transformá-la, para nela intervir, cientes de que mudar é difícil, mas é possível (FREIRE, 1999)

A possibilidade de mudança está diretamente ligada às possibilidades que os trabalhadores têm de estarem juntos, espaços oportunizados para uma pausa no fazer e então compartilharem suas necessidades, dificuldades e construírem uma prática que pode estar fundamentada no conhecimento teórico, mas enriquecida com a vivência real e possível dentro dos serviços de saúde.

Considera-se que para a reconstrução das práticas, é necessária uma eterna reconstrução das pessoas e para isso é preciso uma interação dos sujeitos com o Mundo e dos sujeitos entre si, e desenvolveriam esta capacidade a partir da elaboração reflexiva de suas experiências, rompendo com o saber centralizado e integrando às relações sujeito-objeto, oportunizando aos trabalhadores um potencial para pensar e agir com algum grau de autonomia, conformando-se então em uma práxis social (CAMPOS, 2007)

Entende-se como práxis toda a prática com possibilidade de reflexão, uma ação orientada, planejada e projetada, rompendo com a fragmentação de tarefas e estas realizadas, muitas vezes, por um agir inconsciente (CAMPOS, 2007). A práxis é reflexão e ação do homem sobre a realidade para transformá-la, sendo necessária uma inserção crítica do sujeito no cenário real (FREIRE, 2001)

Ao refletir e compreender a realidade dos cenários em que estão os sujeitos, inicia-se o processo de repensar criticamente sobre as atitudes que eles estão apresentando, sendo possível desenvolver sua criatividade para enfrentar as situações diversas vividas a cada dia, como também a segurança na tomada de decisões.

A contento, o desafio se torna oportunizar espaços formais de reflexão da prática apoiados pelos gestores dos serviços de saúde que precisam priorizar 
este momento e facilitar a participação de seus funcionários. Somente acreditar no processo de mudança não basta, a EP tem que se apresentar nas propostas de prioridades da gestão.

As instituições que acreditam e apoiam os processos de EP têm a oportunidade de qualificarem seus trabalhadores a exercerem suas atividades com segurança, domínio de conhecimentos teóricos e autonomia na tomada de decisões, como evidenciam as publicações analisadas:

\section{[...] Os participantes destacaram a valorização profissional e a autonomia para a realização das atividades relacionadas à competência do enfermeiro, ressaltando a educação permanente como estratégia para aquisição e atualização de conhecimentos e formação de agentes multiplicadores junto aos usuários e à equipe de saúde $\quad[\ldots]$ (P4). [...] A educação permanente em saúde contribuiu para melhorar a qualificação dos profissionais, uniformizar e sistematizar um atendimento ao usuário com diabetes em termos de integralidade, educação em saúde e desenvolvimento do autogerenciamento [...] (P5).}

A decisão em oportunizar a construção da autonomia dos trabalhadores, significa romper com um modelo de gestão fundamentado nas teorias da administração científica que exercem o controle e o poder de decisão, sendo que os trabalhadores renunciam ao seu saber, sua criatividade, exercendo um comportamento mecânico e racional.

Acredita-se que os trabalhadores têm potencial para constituírem coletivos organizados capazes de gerir instituições de saúde, compartilhando o poder sem que se estabeleça o caos (CAMPOS, 2007)

É necessário que estes trabalhadores sejam sujeitos do processo, sendo considerado suas subjetividades, seus desejos, interesses e necessidades, que deverão estar expostos no momento de construção coletiva (CAMPOS, 2007)

A partir do momento em que os sujeitos se fortalecem dominando o conteúdo de seu trabalho, amplia sua esfera de autonomia estabelecendo espaços de discussão, para argumentar, reivindicar e interferir nas decisões do processo de trabalho (PEDIZZI E ANSELMI, 2004)

Os espaços de EP se configuram em um espaço pedagógico, onde há troca de saberes e práticas possibilitando que os sujeitos se reconheçam eticamente por meio da ampliação da autonomia, esta fortalecida pela confiança em si próprio, adquirida pela consciência do conhecimento e da competência pessoal (FREIRE, 1999)

Quando se analisa as pesquisas, percebe-se que a partir dos momentos de integração entre os profissionais durante a 
$\mathrm{EP}$, onde se predomina o diálogo, este, segundo Freire 1999, favorece a aprendizagem e o crescimento na diferença, sendo que se faz necessário o respeito à autonomia e a identidade do outro, surgindo assim uma prática coerente e ética.

Esta prática só é possível quando se prioriza o diálogo entre seus pares, tornando-se sujeitos do processo em que crescem juntos, em que os argumentos de autoridade já não ocupam o lugar de destaque, e esta autoridade se estabelece a partir da liberdade em se posicionar no grupo e refletir criticamente sobre si mesmo e sobre o outro (FREIRE, 2001)

Entende-se que quando se institui a EP como estratégia de educação e gestão dos serviços de saúde, tendo como eixo a metodologia da educação problematizadora, oportunizou a ação reflexão - ação das necessidades de cada trabalhador. Neste sentido, identificou-se a mudança das práticas a partir da autonomia que desenvolvem quando expõem seus saberes e reconhecem as potencialidades do outro, favorecendo assim as tomadas de decisões que se apresentam de forma segura e fortalecida pelo coletivo.

\section{CONCLUSÃO}

Com este estudo permitiu identificar que poucas instituições de saúde têm se aventurado em utilizar-se da EP como estratégia de formação de recursos humanos para à saúde.

Dentre os estudos analisados observou que muitos são os aspectos favoráveis à utilização da EP, oportunizar espaços de escuta e diálogo foi revelado como fator de envolvimento $\mathrm{e}$ responsabilização dos sujeitos, bem como uma oportunidade destes estabelecerem vínculos, construírem uma relação de confiança possibilitando a conscientização da prática vivida se co-responsabilizando com o outro e então é possível a construção de novos saberes.

Outro aspecto que considerou-se relevante ao se implantar a EP foi a construção da autonomia dos trabalhadores, que ao se reconhecerem eticamente, aumentaram a confiança em si próprio e reconheceram sua competência, favorecendo a aprendizagem e consequentemente a qualidade do cuidado.

No entanto, decidir utilizar-se da EP para a formação dos trabalhadores de saúde se configura em uma atitude ousada, pois colocar os trabalhadores como sujeitos do processo de trabalho e gestão é abrir-se para uma nova lógica de organização e cuidado em saúde, onde se faz necessário romper com os modelos de gestão autoritários e os processos de cuidar centralizados no profissional de saúde e não no usuário. 


\section{REFERÊNCIAS}

BARDIN, L. Análise de conteúdo. Lisboa: Edições 70, 1977.

BEYEA, S.C.; NICOLL, L.H. Writing an integrative review. AORN J., New York, v.67, n.4, p.877-80, Apr. 1998.

BRASIL. Ministério da Saúde. Secretaria de Gestão do Trabalho e da Educação na Saúde. Departamento de Gestão da Educação na Saúde. Curso de Formação de Facilitadores de Educação Permanente em Saúde: unidade de aprendizagem: análise do contexto da gestão e das praticas de saúde. Brasília, 2005.

BRASIL. Ministério da Saúde. Secretaria de Atenção à Saúde. Núcleo Técnico da Política Nacional de Humanização.

HumanizaSUS: documento base para gestores e trabalhadores do SUS. 4.ed. Brasília, 2007a.

BRASIL. Ministério da Saúde. Secretaria de Atenção à Saúde. Núcleo Técnico da Política Nacional de Humanização. Clínica ampliada, equipe de referência e projeto terapêutico singular. 2.ed. Brasília, 2007b.

BRASIL. Ministério da Saúde. Secretaria de Atenção à Saúde. Política Nacional de Humanização da Atenção e Gestão do SUS. Gestão participativa e cogestão. Brasília, 2009.

CAMPOS, G.W.S.; AMARAL, M.A. A clínica ampliada e compartilhada, a gestão democrática e redes de atenção como referências teórico-operacionais para a reforma do hospital. Cienc. Saúde Coletiva, Rio de Janeiro, v.12, n.4, p.849859, jul./ago. 2007.

CECCIM, R.B. Educação permanente em saúde: descentralização e disseminação de capacidade pedagógica na saúde. Cienc.
Saúde Coletiva, Rio de Janeiro, v.10, n.4, p.975-986, out./dez. 2005.

CHIESA, A.M.; VERÍSSIMO, M.D.L.O.R. A educação na prática do PSF. In: INSTITUTO PARA O DESENVOLVIMENTO DA SAÚDE IDS; UNIVERSIDADE DE SÃO PAULO - USP; BRASIL. Ministério da Saúde; FUNDAÇÃO TELEFÔNICA. Manual de enfermagem. São Paulo: IDS, 2001. p.3442.

CYRINO, E.G.; TORALLES-PEREIRA, M.L. Trabalhando com estratégias de ensino-aprendizado por descoberta na área de saúde: a problematização e a aprendizagem baseada em problemas.

Cad. Saúde Pública, Rio de Janeiro, v.20, n.3, p.780-788, maio/jun. 2004.

DURÂES-PEREIRA, M.B.B.B.; NOVO, N.F.; ARMOND, J.E. A escuta e o diálogo na assistência ao pré-natal, na periferia da zona Sul, no município de São Paulo.

Cienc. Saúde Coletiva, Rio de Janeiro, v.12, n.2, p.465-476, mar./abr. 2007.

FREIRE, P. Pedagogia da autonomia: saberes necessários à prática educativa. 11.ed. São Paulo: Paz e Terra, 1999.

FREIRE, P. Pedagogia do oprimido. São Paulo: Paz e Terra, 2001.

MERHY, E.E. Saúde: a cartografia do trabalho vivo. 3.ed. São Paulo: Hucitec, 2002.

MATURANA, H.R. Emoções e linguagem na educação e na política. Belo Horizonte: UFMG,1998.

PEDUZZI, M.; ANSELMI, M.L. O auxiliar e o técnico de enfermagem: categorias profissionais diferentes e trabalhos equivalentes. Rev. Bras. Enferm., Brasília, v.57, n.4, p.425-429, jul./ago. 2004. 
SAUPE, R.; BUDÓ, M.L.D. Pedagogia interdisciplinar: educare (educação e cuidado) como objetivo fronteiriço em saúde. Texto \& Contexto Enferm., Florianópolis, v.15, n.2, p.326-333, abr./jun. 2006.

(*)AMESTOY, S.C.; CESTARI, M. E.; THOFEHRN, M.B.; MILBRATH, V.M.; TRINDADE, L.L.; BACKES, V.M.S. Processo de formação de enfermeiros líderes. Rev. Bras. Enferm., Brasília, v.63, n.6, p.940-945, nov./dez. 2010.

(*)BRUM, L.M. A pedagogia da roda como dispositivo de educação permanente em enfermagem e a construção da integralidade do cuidado no contexto hospitalar. 2009. 132f.

Dissertação (Mestrado) - Escola de Enfermagem, Universidade Federal do Rio Grande do Sul, Porto Alegre, 2009.

(*)JESUS, M.C.P.; FIGUEIREDO, M.A.G.; SANTOS, S.M.R.; AMARAL, A.M.M.; ROCHA, L.O.; THIOLLENT, M.J.M. Educação permanente em enfermagem em um hospital universitário. Rev. Esc. Enferm. USP, São Paulo, v.45, n.5, p.1229-1236, out. 2011.

(*)MEDEIROS, A.C.; PEREIRA, Q.L.C.; SIQUEIRA, H.C.H.; CECAGNO, D.; MORAES, C.L. Gestão participativa na educação permanente em saúde: olhar das enfermeiras. Rev. Bras. Enferm., Brasília, v.63, n.1, p.38-42, jan./fev. 2010.

(*)MONTANHA, D.; PEDUZZI, M. Educação permanente em enfermagem: levantamento de necessidades e resultados esperados segundo a cencepção dos trabalhadores. Rev. Esc. Enferm. USP, São Paulo, v.4, n.3, p.597-604, set. 2010.
DST/HIV/Aids. Interface Comum. Saúde Educ., Botucatu, v.12, n.25, p.413-420, abr./jun. 2008.

(*)RICALDONI, C.A.C.; SENA, R.R. Educação permanente: uma ferramenta para pensar e agir no trabalho de enfermagem. Rev. Latinoam. Enferm., Ribeirão Preto, v.14, n.6, p.837-842, nov./dez. 2006. Disponível em: $<$ http://www.scielo.br/pdf/rlae/v14n6/pt_v 14n6a02.pdf $>$. Acesso em: 18 maio 2012.

(*)RODRIGUES, A.C.S.; VIEIRA, G.L.C.; TORRES, H.C. A proposta da educação permanente em saúde na atualização da equipe de saúde em diabetes mellitus. Rev. Esc. Enferm. USP, São Paulo, v.44, n.2, p.531-537, jun. 2010.

(*)NUNES, M.F.; PEREIRA, M.F.; ALVES, R.T.; LELES, C.R. A proposta da educação permanente em saúde na formação de cirurgiões-dentistas em 